\title{
PEMODELAN ARUS LALU LINTAS ROUNDABOUT
}

\author{
NANDA ARDIELNA, MAHDHIVAN SYAFWAN \\ Program Studi Matematika, \\ Fakultas Matematika dan Ilmu Pengetahuan Alam, Universitas Andalas, \\ Kampus UNAND Limau Manis Padang, Indonesia. \\ nardielna@gmail.com
}

\begin{abstract}
Abstrak. Pada artikel ini dijelaskan pemodelan matematika untuk arus lalu lintas di roundabout. Roundabout adalah bentuk desain persimpangan yang menampung arus lalu lintas satu arah di sekitar pulau tengah (central island) dan memberikan prioritas kepada kendaraan dalam roundabout. Dengan menggunakan metode Runge-Kutta orde 4, dilakukan beberapa simulasi pada model. Hasil yang diperoleh menunjukkan bahwa model yang dikembangkan cukup baik dalam mendeskripsikan arus lalu lintas di roundabout.

Kata Kunci: Persamaan transport, roundabout, metode Runge-Kutta.
\end{abstract}

\section{Pendahuluan}

Dalam beberapa tahun terakhir kemacetan lalu lintas menjadi masalah yang cukup akut di beberapa kota besar. Berbagai alternatif solusi desain lalu lintas untuk mengurangi kemacetan telah banyak dikembangkan. Salah satu desain lalu lintas yang dikembangkan tersebut adalah roundabout.

Roundabout adalah bentuk desain persimpangan yang menampung arus lalu lintas satu arah di sekitar pulau tengah (central island) dan memberikan prioritas kepada kendaraan dalam roundabout [7]. Ketika digunakan secara tepat, roundabout secara signifikan dapat meningkatkan kelancaran arus lalu lintas yang ada di persimpangan dengan banyak jalan. Namun di sisi lain roundabout juga dapat menimbulkan kemacetan apabila tidak diterapkan secara tepat, misalnya pada kasus dengan kepadatan lalu lintas di entry point yang tidak berimbang.

Pada kasus yang disebut terakhir, kemacetan akan muncul di sekitar entry point yang kepadatan lalu lintasnya lebih rendah dibandingkan dengan entry point lainnya. Hal ini terjadi karena pengendara di entry point ini harus menunggu untuk masuk ke jalur roundabout yang telah terlebih dahulu dimasuki oleh kendaraan dari entry point yang lebih padat lalu lintasnya. Oleh karena itu, untuk mengoptimalkan arus lalu lintas di roundabout ini, perlu dikembangkan sebuah model yang dapat mendeskripsikan arus lalu lintas pada roundabout. Bentuk paling dasar dan umum dari roundabout berupa jalan melingkar di sekitar pulau tengah dengan empat jalan dua arah yang berpotongan (lihat Gambar 1).

Sistematika penulisan pada artikel ini dibagi atas empat bagian. Pada bagian II dibahas tentang pemodelan arus lalu lintas roundabout. Bagian III berisikan simulasi numerik untuk model roundabout. Pada bagian IV disajikan kesimpulan. 


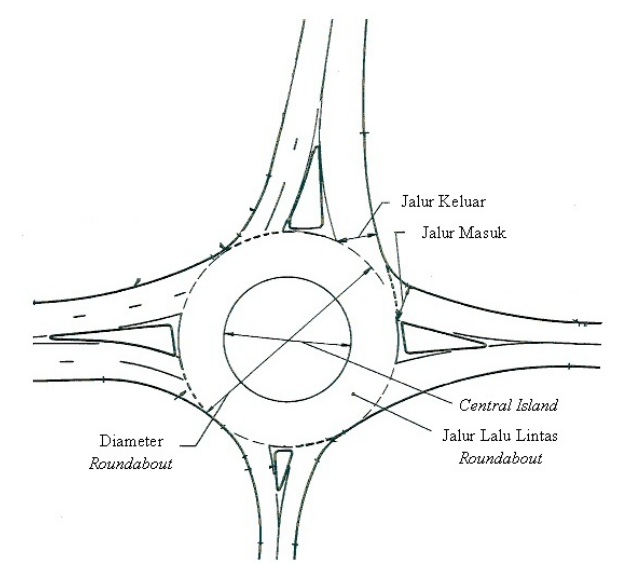

Gambar 1. Ilustrasi roundabout lalu lintas [7]

\section{Pemodelan Arus Lalu Lintas Roundabout}

Pemodelan arus lalu lintas pada roundabout dikembangkan berdasarkan persamaan transport [2]

$$
\frac{\partial \rho(x, t)}{\partial t}+\frac{\partial q(x, t)}{\partial x}=0
$$

Persamaan (2.1) merupakan persamaan diferensial parsial yang mengekspresikan hubungan antara kepadatan lalu lintas $\rho(x, t)$ pada posisi $x$ dan waktu $t$, dengan arus lalu lintas $q(x, t)$ dengan menganggap bahwa banyaknya mobil bersifat kekal. Berikut dijelaskan terlebih dahulu notasi, definisi, dan asumsi yang dipakai pada permasalahan yang dikaji.

\subsection{Notasi dan Definisi}

Beberapa notasi dan definisi yang akan dipakai adalah sebagai berikut.

- Roundabout : persimpangan jalan yang memiliki setidaknya tiga jalur lalu lintas masuk dan tiga jalur lalu lintas keluar.

- Arus lalu lintas $(q)$ : jumlah kendaraan yang melewati suatu titik selama interval waktu tertentu (diukur dalam satuan kendaraan/detik).

- Kepadatan lalu lintas $(\rho)$ : jumlah kendaraan per satuan jarak (diukur dalam satuan kendaraan/meter).

- Kecepatan lalu lintas $(u)$ : laju dari pergerakan arus lalu lintas (diukur dalam satuan meter/detik).

- $u_{\max }$ : kecepatan maksimum lalu lintas di roundabout.

- $\rho_{\max }$ : kepadatan maksimum lalu lintas di roundabout. Berdasarkan data rata-rata panjang mobil, kita tetapkan nilai $\rho_{\max }$ adalah 0,25 kendaraan/meter [3]. 


\subsection{Asumsi}

Asumsi yang dipakai pada model arus lalu lintas roundabout pada artikel ini adalah sebagai berikut.

- Kendaraan yang melaju di lalu lintas roundabout hanyalah mobil dengan panjang yang sama.

- Setiap mobil tidak saling melewati satu sama lain.

- Kecepatan lalu lintas bergantung secara linier pada kepadatan lalu lintas. Ketika kepadatannya nol, maka kecepatan kendaraan yang berada pada lalu lintas mencapai maksimum. Ketika kepadatannya maksimum, maka kecepatannya menjadi nol. Penjelasan lebih detail tentang hal ini akan dibahas pada bagian 2.3 .

- Bentuk geometris dari roundabout adalah lingkaran sempurna.

- Kecepatan maksimum kendaraan di roundabout ditentukan oleh radius roundabout, yaitu

$$
u_{\max }=2,41 r^{0,377} .
$$

Rumus tersebut merupakan hasil regresi dari data National Cooperative High Research Program Report [3].

- Jalan yang mengarah keluar dari roundabout tidak pernah tersumbat atau macet. Ini bertujuan untuk mengoptimalkan roundabout.

- Kendaraan yang memasuki roundabout akan mengambil jalur yang optimal, artinya kendaraan akan berpindah ke jalur yang tepat ketika mereka ingin keluar, dan tetap berada pada jalur tersebut sampai mereka mencapai exit point.

- Tidak ada pejalan kaki atau pengendara sepeda yang melintasi roundabout.

\subsection{Model Kepadatan-Kecepatan Linier}

Diasumsikan bahwa kecepatan mobil bergantung pada kepadatan lalu lintas, bukan pada waktu atau posisi mobil di sepanjang jalan (lihat Gambar 2). Karena arus lalu lintas sama dengan kepadatan dikalikan dengan kecepatan [2], maka berlaku hubungan sebagai berikut.

$$
q=\rho u(\rho) .
$$

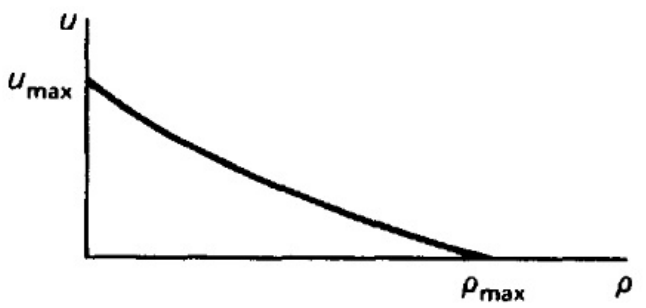

Gambar 2. Kecepatan mobil bergantung pada kepadatan lalu lintas 
Dari hubungan di atas dapat disimpulkan bahwa arus bernilai nol jika :

(1) Tidak ada lalu lintas $(\rho=0)$, atau

(2) Lalu lintas tidak bergerak $\left(u=0\right.$ sehingga $\left.\rho=\rho_{\max }\right)$.

Jika diasumsikan $u(\rho)$ linier, maka berlaku

$$
q=u_{\max }\left(\rho-\frac{\rho^{2}}{\rho_{\max }}\right) .
$$

\subsection{Model "Exits and Entrances"}

Anggap tidak ada mobil yang masuk atau keluar kecuali di titik-titik ujung jalan. Pada bagian ini akan dibahas pengembangan model lalu lintas yang mempertimbangkan mobil masuk dan keluar di dalam segmen jalan, sebagaimana yang diilustrasikan pada Gambar 3.

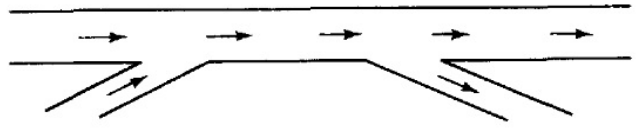

Gambar 3. Mobil keluar dan masuk di dalam segmen jalan

Laju perubahan jumlah mobil antara $x=x_{1}$ dan $x=x_{2}$ bukan hanya ditentukan oleh jumlah mobil yang melintasi $x=x_{1}$ dan $x=x_{2}$ saja, tetapi juga dari jumlah mobil yang masuk atau keluar antara $x=x_{1}$ dan $x=x_{2}$. Misalkan $\int_{x_{1}}^{x_{2}} \beta(x, t) d x$ adalah selisih jumlah mobil yang masuk dan keluar di dalam segmen jalan per satuan jarak antara $x=x_{1}$ dan $x=x_{2}$. Dengan demikian, hukum kekekalan mobil dapat dinyatakan sebagai [2]

$$
\frac{\partial}{\partial t} \int_{x_{1}}^{x_{2}} \rho(x, t) d x=q\left(x_{2}, t\right)-q\left(x_{1}, t\right)+\int_{x_{1}}^{x_{2}} \beta(x, t) d x,
$$

sehingga berlaku

$$
\frac{\partial \rho(x, t)}{\partial t}+\frac{\partial q(x, t)}{\partial x}=\beta(x, t)
$$

Jika $q=q(\rho)$, maka dengan menggunakan aturan rantai, (2.6) dapat ditulis

$$
\frac{\partial \rho}{\partial t}+\frac{d q}{d \rho} \frac{\partial \rho}{\partial x}=\beta
$$

Dengan mensubstitusikan (2.4) ke (2.7), model lalu lintas dapat ditulis

$$
\frac{\partial \rho(x, t)}{\partial t}+u_{\max }\left(1-\frac{2 \rho(x, t)}{\rho_{\max }}\right) \frac{\partial \rho(x, t)}{\partial x}=\beta(x, t) .
$$

\section{Simulasi Numerik}

Untuk memperoleh penyelesaian numerik dari model arus lalu lintas roundabout yang diberikan oleh persamaan (2.8). Metode numerik yang digunakan adalah Runge-Kutta orde 4. 


\subsection{Setting Numerik}

Misalkan akan diselesaikan persamaan differensial parsial (2.8) pada $x \in[0, L]$ dan $t \geq 0$ dengan menggunakan metode Runge-Kutta orde 4 . Selang $[0, L]$ dipartisi dengan ukuran $\Delta x$ sedemikian sehingga titik-titik partisi adalah $x_{j}=j \Delta x, j=$ $0,1, \cdots, N$. Dengan demikian nilai $\rho\left(x_{j}, t\right)$ dan $\beta\left(x_{j}, t\right)$ diaproksimasi oleh

$$
\begin{aligned}
& \rho\left(x_{j}, t\right)=\rho(j \Delta x, t) \approx \rho_{j}, \\
& \beta\left(x_{j}, t\right)=\beta(j \Delta x, t) \approx \beta_{j} .
\end{aligned}
$$

Untuk $\frac{\partial \rho}{\partial x}$, digunakan aproksimasi beda tengah

$$
\frac{\partial \rho}{\partial x} \approx \frac{\rho_{j+1}-\rho_{j-1}}{2 \Delta x} .
$$

Jadi persamaan beda untuk persamaan differensial parsial (2.8) adalah

$$
\rho_{j}^{\prime}(t)=\beta_{j}-u_{\max }\left(1-\frac{2 \rho_{j}}{\rho_{\max }}\right)\left(\frac{\rho_{j+1}-\rho_{j-1}}{2 \Delta x}\right) .
$$

Karena jalur lalu lintas berbentuk lingkaran, digunakan syarat batas periodik $\rho_{N+1}=\rho_{1}$ dan $\rho_{-1}=\rho_{N-1}$, sehingga persamaan beda (3.4) dapat ditulis dalam bentuk vektor sebagai berikut :

$$
\mathbf{p}^{\prime}(t)=\mathbf{b}-u_{\max }\left(\mathbf{1}-\frac{2 \mathbf{p}}{\rho_{\max }}\right)\left(\frac{\mathbf{p}_{p}-\mathbf{p}_{m}}{2 \Delta x}\right),
$$

dimana

$$
\mathbf{p}=\left[\begin{array}{c}
\rho_{0} \\
\rho_{1} \\
\vdots \\
\rho_{N}
\end{array}\right] \quad, \quad \mathbf{b}=\left[\begin{array}{c}
\beta_{0} \\
\beta_{1} \\
\vdots \\
\beta_{N}
\end{array}\right] \quad, \quad \mathbf{p}_{p}=\left[\begin{array}{c}
\rho_{1} \\
\rho_{2} \\
\vdots \\
\rho_{N} \\
\rho_{1}
\end{array}\right] \quad, \quad \mathbf{p}_{m}=\left[\begin{array}{c}
\rho_{N-1} \\
\rho_{0} \\
\vdots \\
\rho_{N-1}
\end{array}\right]
$$

Sisi kanan persamaan (3.5) dapat ditulis

$$
\mathbf{f}(\mathbf{p}(t))=\mathbf{b}-u_{\max }\left(\mathbf{1}-\frac{2 \mathbf{p}}{\rho_{\max }}\right)\left(\frac{\mathbf{p}_{p}-\mathbf{p}_{m}}{2 \Delta x}\right) .
$$

Persamaan iterasi dari metode Runge-Kutta orde 4 untuk persamaan (3.5) adalah

$$
\mathbf{p}_{n+1}=\mathbf{p}_{n}+\frac{h}{6}\left(\mathbf{k}_{1}+2 \mathbf{k}_{2}+2 \mathbf{k}_{3}+\mathbf{k}_{4}\right),
$$

dengan

$$
\begin{aligned}
& \mathbf{k}_{1}=\mathbf{f}\left(\mathbf{p}_{n}\right) \\
& \mathbf{k}_{2}=\mathbf{f}\left(\mathbf{p}_{n}+\frac{h}{2} \mathbf{k}_{1}\right), \\
& \mathbf{k}_{3}=\mathbf{f}\left(\mathbf{p}_{n}+\frac{h}{2} \mathbf{k}_{2}\right), \\
& \mathbf{k}_{4}=\mathbf{f}\left(\mathbf{p}_{n}+h \mathbf{k}_{3}\right) .
\end{aligned}
$$




\subsection{Simulasi}

Simulasi numerik dari model lalu lintas roundabout dengan menggunakan metode Runge-Kutta orde 4 sebagaimana yang sudah dikonstruksi pada bagian sebelumnya. Adapun nilai-nilai parameter yang digunakan pada simulasi ini adalah $: r=10$ dan $\rho_{\max }=0,25$. Dari hubungan $(2.2)$ diperoleh $u_{\max }=2,41 \cdot 10^{0,377} \approx 5,1$. Karena bentuk geometris roundabout dianggap lingkaran sempurna, maka panjang jalur roundabout adalah $L=2 \pi \cdot 10 \approx 63$. Kemudian perhatikan bahwa jalur roundabout dengan panjang $L$ (lihat Gambar 4) dapat "dibuka" sedemikian sehingga membentuk jalur lurus dengan exit-entry point berada di antara titik ujung $x=0$ dan $x=L$ (lihat Gambar 5). Pada kedua gambar juga dapat dilihat perbandingan diskritisasi antara roundabout dan bukaannya.

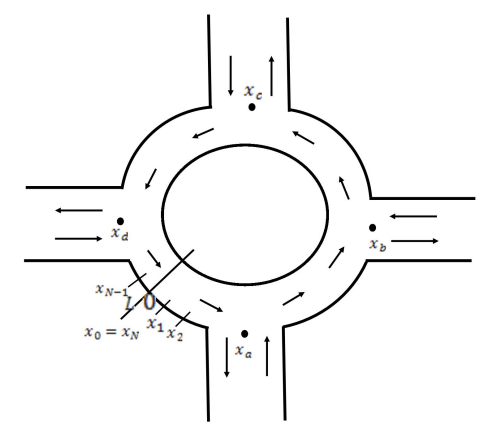

Gambar 4. Jalur roundabout yang didiskritisasi

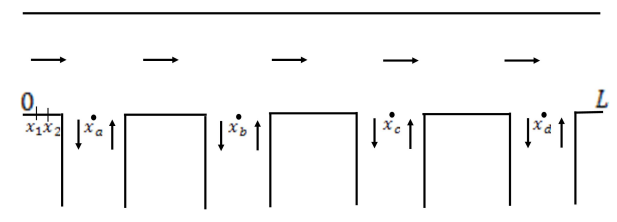

Gambar 5. Jalur roundabout yang "dibuka" dan diskritisasinya (bandingkan dengan Gambar 4).

Dilakukan simulasi dengan beberapa skenario sebagai berikut :

(1) Skenario $1: \beta(x, t)=0$

Pada skenario ini roundabout dianggap tidak memiliki exit-entry point (menjadi lalu lintas "lingkaran"). Pada skenario ini, model akan disimulasikan untuk dua nilai awal berikut:

$$
\rho(x, 0)=0,1
$$


dan

$$
\rho(x, 0)=0,1 \times \operatorname{sech}\left\{\frac{\left(x-\frac{L}{2}\right)}{2}\right\} .
$$

Pada persamaan (3.8), nilai kepadatan awal lalu lintas di roundabout seragam di sepanjang jalur, sedangkan pada persamaan (3.9) nilai kepadatan awal lalu lintas di roundabout lebih tinggi di pertengahan jalur (kendaraan lebih banyak menumpuk di tengah-tengah). Skenario 1 dengan nilai awal (3.8) dan (3.9) ini diberikan pada Gambar 6 dan 7 .

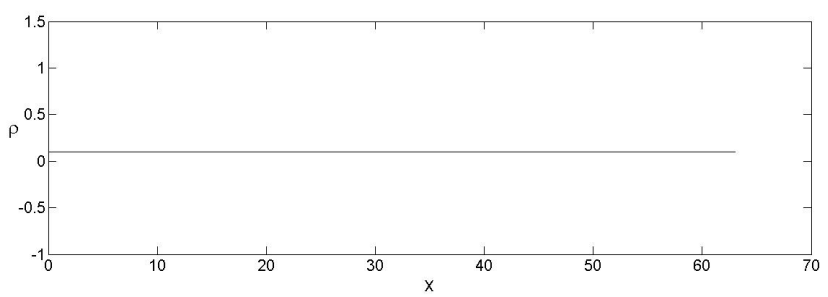

Gambar 6. Simulasi kepadatan lalu lintas di roundabout tanpa exit-entry point $(\beta(x, t)=0)$ dengan nilai awal (3.8) dan dijalankan sampai $t=0,9$.

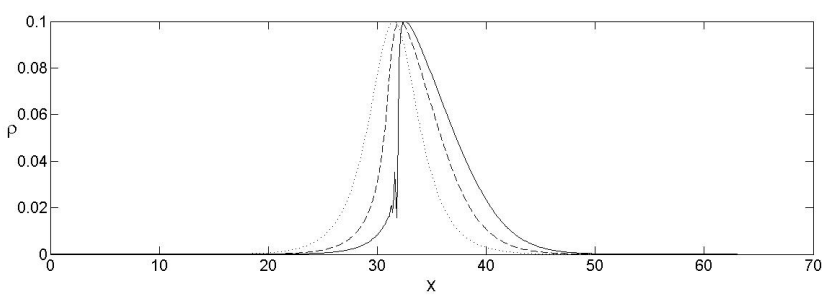

Gambar 7. Simulasi kepadatan lalu lintas di roundabout tanpa exit-entry point $(\beta(x, t)=0)$ dengan nilai awal (3.9) pada saat $t=0$ (garis titik-titik), $t=0,5$ (garis putus-putus), dan $t=0,9$ (garis utuh)

Pada Gambar 6 dapat dilihat bahwa kepadatan lalu lintas selalu konstan di sepanjang jalur roundabout untuk setiap waktu $t$. Hal yang berbeda terjadi pada Gambar 7. Pada kasus ini kepadatan lalu lintas yang awalnya menumpuk ditengah-tengah secara simetris kemudian mengalami pergeseran dengan kepadatan yang tidak lagi simetris (kendaraan lebih banyak menumpuk di bagian belakang). Hal ini terjadi karena semakin tinggi kepadatan lalu lintas, maka kecepatan akan semakin lambat. Jika hal ini terjadi terus menerus, maka suatu ketika akan terjadi chaos (mobil akan bertabrakan). Kondisi chaos ini direpresentasikan oleh garis utuh pada Gambar 7 .

(2) Skenario $2: \beta(x, t) \neq 0$

Pada skenario ini roundabout memiliki exit-entry point dan anggap tidak ada lalu lintas di roundabout pada awalnya $(\rho(x, 0)=0)$. Model pada skenario ini 
akan disimulasikan untuk dua nilai awal berikut :

$$
\beta(x, t)=0,1
$$

dan

$$
\begin{aligned}
\beta(x, t)= & 0,1 \times \operatorname{sech}\left(x-\frac{L}{8}\right)-0,01 \times \operatorname{sech}\left(x-\frac{3 L}{8}\right) \\
& +0,01 \times \operatorname{sech}\left(x-\frac{7 L}{8}\right) .
\end{aligned}
$$

Pada persamaan (3.10), selisih jumlah mobil yang keluar dan yang masuk dibuat seragam. Pada persamaan (3.11), selisih jumlah mobil yang keluar dan yang masuk dibuat berbeda-beda di tiap exit-entry point. Apabila posisi exit-entry point ke- $n$ adalah $x=(2 n-1) \frac{L}{8}$, maka nilai awal (3.11) berarti :

(a) Jumlah mobil yang masuk di exit-entry point pertama lebih banyak dibandingkan dengan mobil yang keluar.

(b) Jumlah mobil yang masuk di exit-entry point kedua lebih sedikit dibandingkan dengan mobil yang keluar.

(c) Jumlah mobil yang masuk di exit-entry point ketiga sama dengan mobil yang keluar.

(d) Jumlah mobil yang masuk di exit-entry point keempat lebih banyak dibandingkan dengan mobil yang keluar, namun selisihnya lebih kecil dibandingkan di exit-entry point pertama.

Hasil simulasi untuk skenario kedua nilai awal diberikan pada Gambar 8 dan 9 .

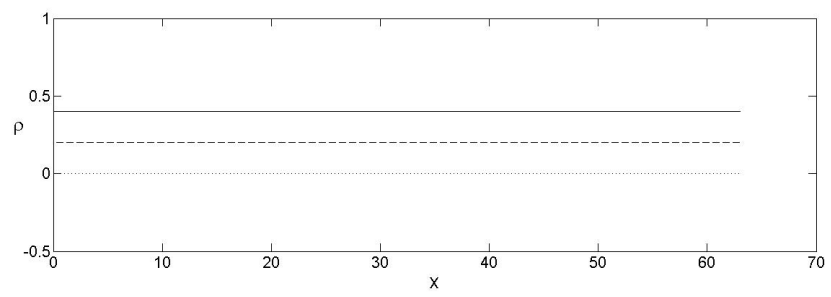

Gambar 8. Simulasi kepadatan lalu lintas di roundabout dengan exit-entry point $(\beta(x, t) \neq 0)$ dengan nilai awal (3.10) pada saat $t=0$ (garis titik-titik), $t=2$ (garis putus-putus), dan $t=4$ (garis utuh)

Pada Gambar 8 dapat dilihat bahwa selisih jumlah mobil masuk-keluar yang seragam mengakibatkan kepadatan bertambah secara konstan di sepanjang jalur roundabout untuk setiap waktu $t$. Sedangkan dari Gambar 9, kurva kepadatan di setiap exit-entry point berbeda-beda sebagai akibat dari selisih jumlah mobil di sekitar exit-entry point yang juga berbeda. Seiring bertambahnya waktu, nilai kepadatan juga bertambah namun mengalami pergeseran di sepanjang $x$. Pada saat $t=4$ diperoleh hasil bahwa kepadatan maksimum terjadi di daerah sesudah exit-entry point pertama. Hal ini berarti bahwa kemacetan awal akan berpotensi terjadi di daerah tersebut. Ingat kembali bahwa selisih jumlah mobil yang masuk dan keluar di exit-entry point pertama lebih besar 


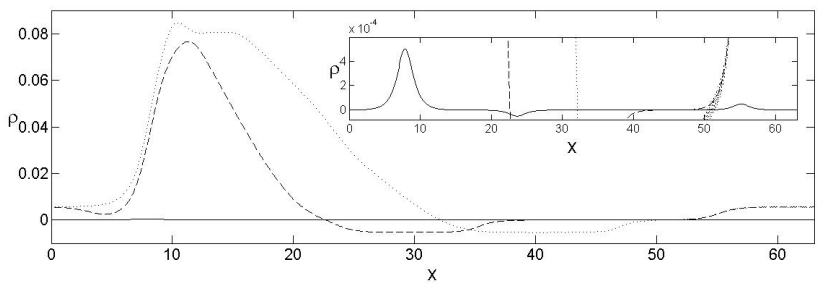

Gambar 9. Simulasi kepadatan lalu lintas di roundabout dengan exit-entry point $(\beta(x, t) \neq 0)$ dengan nilai awal (3.11) pada saat $t=0$ (garis titik-titik), $t=2$ (garis putus-putus), dan $t=4$ (garis utuh)

dibandingkan yang lain. Perhatikan bahwa pada simulasi ini, kepadatan $\rho(x, t)$ bernilai negatif untuk suatu interval $x$, sehingga menjadi tidak realistis. Hal ini kemungkinan karena asumsi (3.5) tidak terpenuhi.

\section{Kesimpulan}

Berdasarkan hasil-hasil simulasi yang diperoleh, dapat diberikan kesimpulan sebagai berikut.

(1) Apabila roundabout dianggap tidak memiliki exit-entry point (lalu lintas lingkaran), maka kepadatan lalu lintas yang awalnya konstan (seragam) akan selalu konstan di sepanjang waktu. Namun jika kepadatan awal lalu lintas tidak seragam, maka seiring berjalannya waktu, kendaraan akan semakin banyak menumpuk di bagian belakang daerah yang memiliki nilai kepadatan yang lebih besar, sehingga suatu ketika akan terjadi chaos (bertabrakan).

(2) Apabila roundabout memiliki exit-entry point dan anggap tidak ada lalu lintas pada awalnya, maka selisih jumlah mobil masuk-keluar yang seragam (kons$\operatorname{tan)~mengakibatkan~kepadatan~lalu~lintas~di~roundabout~juga~seragam~namun~}$ nilainya semakin lama semakin naik. Di sisi lain, selisih jumlah mobil masukkeluar yang tidak seragam mengakibatkan kepadatan lalu lintas yang juga tidak seragam. Menariknya, kemacetan awal di roundabout akan berpotensi terjadi di daerah sesudah exit-entry point dimana selisih jumlah mobil masuk-keluar lebih besar dibandingkan dengan exit-entry point lainnya.

\section{Ucapan Terima kasih}

Penulis mengucapkan terima kasih kepada Ibu Susila Bahri, Bapak Budi Rudianto dan Bapak Efendi yang telah memberikan masukan dan saran dalam penyempurnaan penulisan artikel ini.

\section{Daftar Pustaka}

[1] Budhi, Wono Setya. 2001. Kalkulus Peubah Banyak dan Penggunaannya. ITB Bandung. Bandung

[2] Haberman, Richard. 1977. Mathematical Models: Mechanical Vibrations, Populations Dynamics, and Traffic Flow. Prentice-Hall, Englewood Cliffs. New Jersey 
52 Nanda Ardielna dan Mahdhivan Syafwan

[3] Hachey Simon, dkk. 2009. Modeling Roundabout Traffic Flow as a Dynamic Fluid System. www.math.washington.edu/ morrow/mcm/4329.pdf. Diakses pada 5 Agustus 2013. 14:20 WIB

[4] Iserles, Arieh. 2009. A First Course in the Numerical Analysis of Differential Equations. Cambridge University Press. New York

[5] Kreyszig, Erwin. 2011. Advanced Engineering Mathematics. John Wiley dan Sons. New York

[6] Straus, A. Walter. 1992. Partial Differential Equations : an Introduction. John Wiley dan Sons. New York

[7] Taekratok, Thaweesak. 1998. Modern Roundabouts For Oregon. www.oregon.gov/ODOT/hwy/engservices/docs/modernroundabouts.pdf. Diakses pada 5 Agustus 2013. 14:30 WIB. 